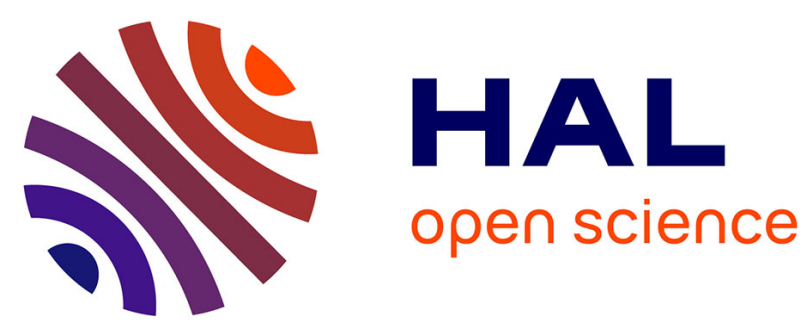

\title{
Repeatability and validation of Gait Deviation Index in children: Typically developing and cerebral palsy
}

\author{
Abir Massaad, Ayman Assi, Wafa Skalli, Ismat Ghanem
}

\section{To cite this version:}

Abir Massaad, Ayman Assi, Wafa Skalli, Ismat Ghanem. Repeatability and validation of Gait Deviation Index in children: Typically developing and cerebral palsy. Gait \& Posture, 2014, 39 (1), pp.354-358. 10.1016/j.gaitpost.2013.08.001 . hal-03255677

\section{HAL Id: hal-03255677 \\ https://hal.science/hal-03255677}

Submitted on 9 Jun 2021

HAL is a multi-disciplinary open access archive for the deposit and dissemination of scientific research documents, whether they are published or not. The documents may come from teaching and research institutions in France or abroad, or from public or private research centers.
L'archive ouverte pluridisciplinaire HAL, est destinée au dépôt et à la diffusion de documents scientifiques de niveau recherche, publiés ou non, émanant des établissements d'enseignement et de recherche français ou étrangers, des laboratoires publics ou privés. 


\title{
Repeatability and validation of Gait Deviation Index in children: Typically developing and cerebral palsy
}

\author{
Abir Massaad ${ }^{\mathrm{a}, *}$, Ayman Assi ${ }^{\mathrm{a}, \mathrm{b}, \mathrm{c}}$, Wafa Skalli ${ }^{\mathrm{c}}$, Ismat Ghanem ${ }^{\mathrm{a}, \mathrm{b}, \mathrm{d}}$ \\ ${ }^{a}$ Gait and Motion analysis Laboratory, Sesobel, Aintoura, Lebanon \\ ${ }^{\mathrm{b}}$ Laboratory of Biomechanics, Faculty of Medicine - PTS, University of Saint-Joseph, Beirut, Lebanon \\ ' Laboratoire de Biomécanique, Arts et Métiers ParisTech, 151, Boulevard de l'Hôpital, 75013 Paris, France \\ ${ }^{\mathrm{d}}$ Hôpital Hôtel Dieu de France, Avenue Alfred Naccache, Achrafieh, Beirut, Lebanon
}

\begin{abstract}
A B S T R A C T
The Gait Deviation Index (GDI) is a dimensionless parameter that evaluates the deviation of kinematic gait from a control database. The GDI can be used to stratify gait pathology in children with cerebral palsy (CP). In this paper the repeatability and uncertainty of the GDI were evaluated. The Correlation between the GDI and the Gross Motor Function Classification System (GMFCS) was studied for different groups of children with CP (hemiplegia, diplegia, triplegia and quadriplegia). Forty-nine, typically developing children (TD) formed our database. A retrospective study was conducted on our 3D gait data and clinical exams and 134 spastic children were included. Sixteen TD children completed the gait analysis twice to evaluate the repeatability of the GDI (test-retest evaluation). Monte Carlo simulations were applied for all groups (TD and children with $\mathrm{CP}$ ) in order to evaluate the propagation of errors stemming from kinematics. The repeatability coefficient (2SD of test-retest differences), obtained on the GDI for the 16 TD children ( 32 lower limbs) was \pm 10 . Monte Carlo simulations showed an uncertainty ranging between 0.8 and 1.3 for TD children and all groups with CP. The Spearman Rank correlation showed a moderate correlation between the GDI and the GMFCS $(r=-0.44, p<0.0001)$.
\end{abstract}

\section{Introduction}

Given the different gait patterns and pathologies in children with cerebral palsy (CP), a global analysis is essential in clinical practice. For this purpose, estimation of gait deviations from normative values is required and is helpful to improve therapeutic interventions.

In the $\mathrm{CP}$ pathology, three dimensional (3D) gait analysis for ambulant children and clinical evaluations are commonly used as assessments and are part of the international standard of CP care [1]. Even with 3D gait analysis, which is becoming an essential tool to assess ambulant children with $\mathrm{CP}$ [2], it is sometimes difficult to define objectively the amount of abnormalities and the degree by which an abnormal gait deviates from normal patterns. Three dimensional (3D) gait analysis provides a large amount of interdependent data and variables corresponding to different gait patterns [3]. The quantity and complexity of the data have pushed many authors to describe indices based on 3D gait analysis, developed primarily to evaluate clinical changes after a therapeutic intervention like the hip flexor index (HFI) [4] and the Gillette Gait Index (GGI) [5]. The GGI is calculated using discrete parameters incorporating 16 kinematic and temporal distance variables, chosen arbitrarily, allowing us to describe and to quantify the amount of pathology in an individual's gait pattern, and its repeatability has been evaluated [6]. These tools ignore the relation that exists between gait variables, contrary to other indices, described later, like the Gait Profile Score (GPS) [3] and the Gait Deviation Index (GDI) [7]. The GDI is an alternative to the GGI, measuring the subject's gait deviation from a normative database. It is calculated using kinematic variables, studied point by point, during the entire gait cycle. It is a scaled distance between 9 kinematic parameters of pathological gait and the average of 9 kinematic parameters of normal gait (group of typically developing (TD) children) [8]. The GDI is represented as a single number: when the number decreases, clinical involvement increases, and when the number increases, the gait profile is closer to a normal profile $(\geq 100)$.

Many authors were interested in studying the correlation between indices calculated from the computerized gait analysis and clinical evaluation tools [9-11]. Molloy [12] studied the correlation between the GDI and clinical functional measures like the Gross Motor Function Measure (GMFM) and Gross Motor 
Function Classification system (GMFCS) and concluded that the GDI is a valid tool to describe motor impairments in CP.

However, for clinical use, it would be interesting to evaluate the repeatability of the GDI, by the test-retest method, since there is no previous study on this subject. Moreover, the method of calculation of the GDI involves kinematic curves and their transformation into vectors, matrices, euclidian distances and singular value decomposition [7]. Kinematics are subject to errors in $3 \mathrm{D}$ gait analysis and these errors can lead to uncertainties on the value of the GDI. It would be interesting to evaluate the propagation of errors during the calculation of the GDI.

The aim of this study is to evaluate the repeatability of the GDI within typically developing (TD) children. The error propagation during the calculation of the GDI was evaluated by applying Monte Carlo simulations on TD children and children with CP.

\section{Methods}

\subsection{Samples}

A retrospective study was conducted on our 3D gait data and clinical assessments performed between 2006 and 2012. One hundred ninety one $(N=191)$ children were referred to our gait laboratory for an orthopedic evaluation, an orthotic intervention or for a baseline gait assessment. Forty-nine $(N=49)$ TD children formed our asymptomatic database with a mean age of 10.3 years $(\mathrm{SD}=3$, minimum $=5$ years, maximum $=15$ years $)[6]$. One hundred thirty four $(N=134)$ children with the diagnosis of spastic cerebral palsy were included in this study with a mean age of 10.5 years $(S D=4.5$, minimum $=5$ years, maximum $=20$ years $)$. Six Vicon MX3 cameras were used for the data acquisition (Vicon Motion Systems, Oxford, UK). Sixteen reflective markers based on the Davis protocol [2] were placed to calculate joint kinematic angles. Six to seven trials at self-selected walking speed were collected for each subject and one representative cycle for a barefoot stride for each limb was selected, for each subject, jointly by a bioengineer and a physical therapist, both experienced in gait analysis. The GMFCS score was assessed by the physical therapist during the clinical examination, which was carried out immediately before the subject underwent 3D gait analysis.

Each child was classified by the referring clinician, according to the distribution of spasticity and limb involvement during visual gait assessment and clinical examination. Children with hemiplegia $(N=31)$ have one lower limb involved with the ipsilateral upper limb. Children with diplegia $(N=86)$ have both lower limbs involved with minimal involvement of the upper limbs, while children with trilpegia $(N=6)$ present spasticity in the lower limbs with major involvement of one upper limb. Quadriplegia $(N=11)$ is characterized by moderate to severe involvement of the four limbs. The GDI score was calculated in a Matlab (Mathworks ${ }^{\circledR}$, Natick, MA, USA) function, separately for each leg, using the method provided by Schwartz [7]. Nine kinematic variables are used for this calculation: pelvis and hip motion in the 3 planes (sagittal, frontal, horizontal), knee and ankle motion in the sagittal plane and the foot progression angle in the horizontal plane [7].

The database of TD children, available in our laboratory ( $N=49$ subjects) was divided into 2 groups: the reference group ( $N=33$ who performed the gait analysis one time) and the ablebodied group ( $N=16$ subjects who performed the exam twice at one week interval). The reference group formed the database for GDI calculation. The calculation of the GDI for the able-bodied group helped in the verification of GDI implementation. The repeatability of the GDI was calculated on the 32 lower limbs from the 16 TD children who formed the able-bodied group. The correlation between the GDI and the GMFCS was evaluated on the groups with $\mathrm{CP}$.

\subsection{Monte Carlo simulations}

In order to evaluate the sensitivity of the GDI to the variability of kinematic parameters, Monte Carlo simulations were applied on the able-bodied group and on each group of children with CP. Monte Carlo simulations are widely used in biomedical studies to assess the propagation of uncertainties in a calculation process $[6,13]$. The application of this simulation requires: definition of the measurand (the mathematical model), association of uncertainty on each variable entry, generation of $N$ random realizations of entry, calculation of the $N$ measurands and their standard deviations (95\% confidence interval: mean $\pm 2 \mathrm{SD}$ ), via the model. In this study, the measurand defined is the GDI. The variable entries are the kinematic curves of the subjects. Ten thousand random realizations of entries were created by adding a random noise to each curve. The means of the random noises were set to zero and the standard deviations were the same as the intersession variability found on each kinematic parameter in our laboratory [6]. The standard deviations were those found on the overall range of motion for each joint/segment (pelvis, hip, knee, ankle, foot progression) in each plane of interest (sagittal, frontal and horizontal). Ten thousand values of the GDI were obtained and their standard deviations were calculated (95\% confidence interval by calculating the $2 \mathrm{SD}$ ).

\subsection{Statistical analysis}

Xlstat $^{\circledR}$ (Addinsoft, New York, USA) and Matlab ${ }^{\circledR}$ (Mathworks ${ }^{\circledR}$, Natick, MA, USA) were used for statistical calculations. The Shapiro Wilk test was applied to study the distribution of all the variables. The Fisher test was applied in order to verify the equality of variances, then, the Student paired $t$-test was applied to compare the average of the GDI between session 1 and session 2 for the 16 TD children who completed the exam twice. The confidence interval was evaluated by calculating 2SD of the difference between the 2 sessions, by using the method described by Bland and Altman $[14,15]$ : there were two samples of GDI values $\left(x_{i, 1}\right.$ and $x_{i, 2}$ ) from the two sessions of the 16 subjects who completed the gait analysis twice (index $i$ referring to subject's number). To evaluate the extent of the differences between repeated tests a within-subject inter-sessions difference was calculated, $D_{i}=(x$ ${ }_{i}, 1-x_{i, 2}$ ). The coefficient of repeatability was 2SD of the 16 values of $D_{i}$, as reported by Bland and Altman.

One way Anova with Duncan's post hoc test was applied to determine the ability of the GDI to differentiate between children with cerebral palsy, defined by their topographic classifications and GMFCS levels. A Power analysis was performed. The Spearman Rank correlation was applied to study the correlation between the GMFCS and the GDI. Significance level was set to 0.05 for all tests.

\section{Results}

\subsection{GDI for children with $C P$}

The demographic characteristics of the children with CP and TD children are summarized in Table 1. The GDI was calculated separately for each lower limb. The GDI was normally distributed in each GMFCS level for children with CP and for TD children. The mean value of the GDI according to GMFCS levels is represented in Table 2. The mean value of the GDI decreases when the GMFCS increases. The histogram of the GDI is shifted toward 100 when the GMFCS decreases (Fig. 1 (left)). The mean values of the GDI (mean $\pm 1 S D$ ) for the different groups of children with CP are presented in Table 2. We noticed an overlap of GDI values for various $\mathrm{CP}$ sub-types most noted between hemiplegia, diplegia and triplegia (Fig. 1 (right)). 

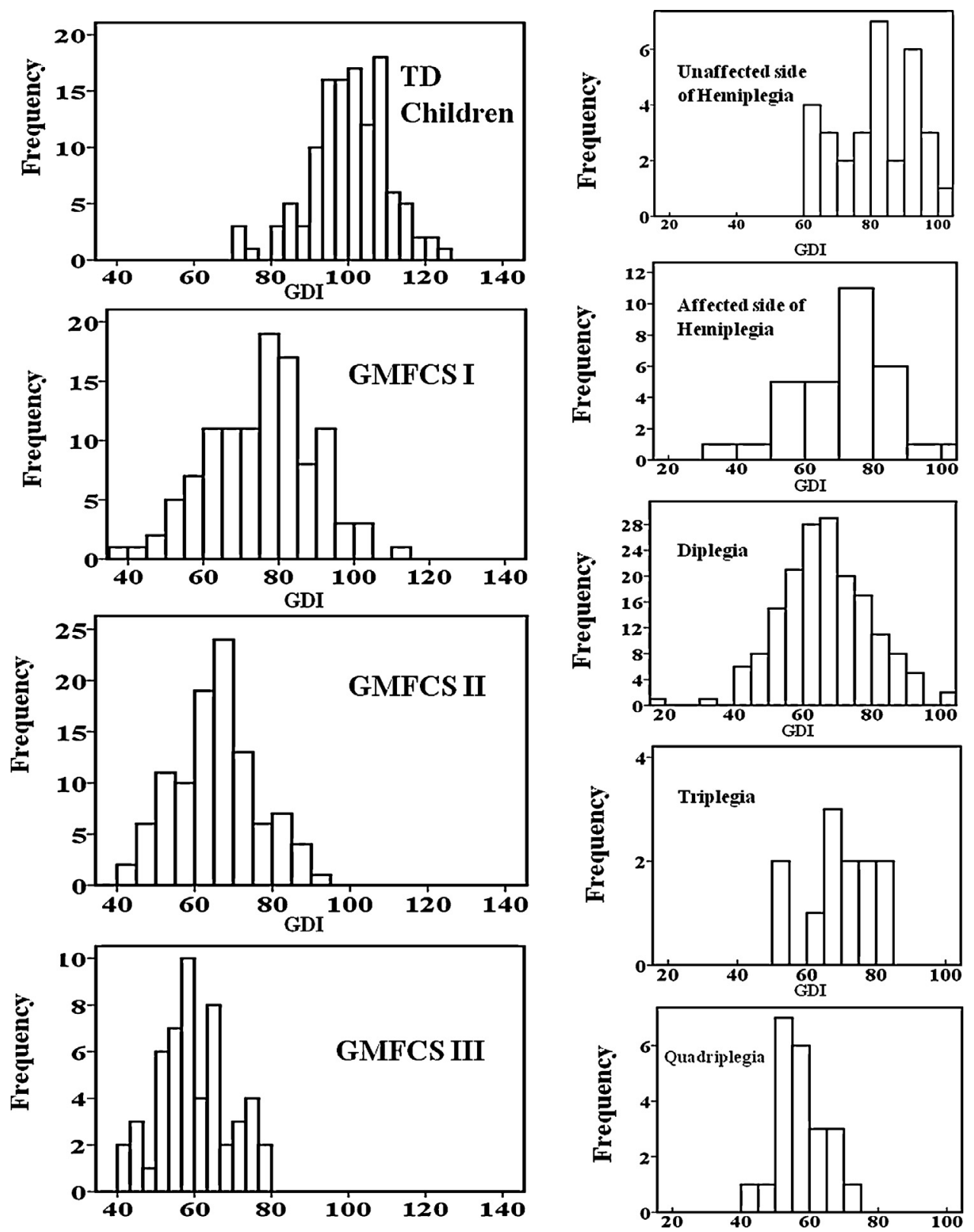

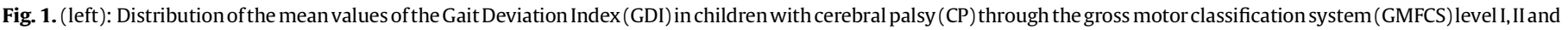

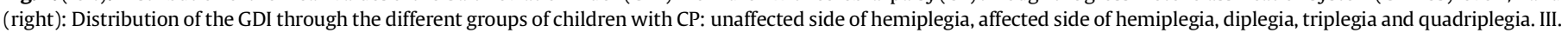

Table 1

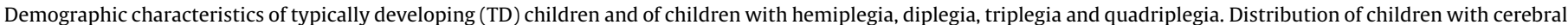
palsy (CP) according to Gross Motor Function Classification System (GMFCS) level.

\begin{tabular}{|c|c|c|c|c|c|c|c|}
\hline \multirow[t]{2}{*}{ Groups } & \multirow[t]{2}{*}{$N$} & \multirow{2}{*}{$\begin{array}{l}\text { Age } \\
\text { Mean } \pm 1 S D\end{array}$} & \multirow{2}{*}{$\begin{array}{l}\text { Height }(\mathrm{cm}) \\
\text { Mean } \pm 1 S D\end{array}$} & \multirow{2}{*}{$\begin{array}{l}\text { Weight }(\mathrm{kg}) \\
\text { Mean } \pm 1 \mathrm{SD}\end{array}$} & \multirow[t]{2}{*}{ GMFCS level I ( $n$ ) } & \multirow[t]{2}{*}{ GMFCS level II $(n)$} & \multirow[t]{2}{*}{ GMFCS level III $(n)$} \\
\hline & & & & & & & \\
\hline TD children & 49 & $10.3 \pm 3$ & $144 \pm 16.8$ & $43.4 \pm 17.1$ & & & \\
\hline Hemiplegia & 31 & $9.8 \pm 5$ & $132 \pm 25.3$ & $36.2 \pm 21.3$ & 27 & 4 & 0 \\
\hline Diplegia & 86 & $10.5 \pm 4.2$ & $130.2 \pm 18.4$ & $33.5 \pm 15.1$ & 27 & 40 & 19 \\
\hline Triplegia & 6 & $12.6 \pm 6.6$ & $140.8 \pm 27.3$ & $41.5 \pm 25.7$ & 3 & 3 & 0 \\
\hline Quadriplegia & 11 & $16 \pm 5.4$ & $144 \pm 15$ & $44.8 \pm 20.7$ & 0 & 4 & 7 \\
\hline
\end{tabular}

Table 2

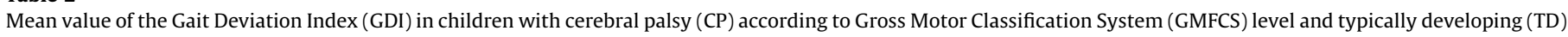
children.

\begin{tabular}{|c|c|c|c|c|c|}
\hline & \multicolumn{3}{|c|}{ Children with $\mathrm{CP}$} & \multicolumn{2}{|l|}{ TD Children } \\
\hline & GMFCS I & GMFCS II & GMFCS III & Reference group & Able-bodied group \\
\hline$N$ & 57 & 51 & 26 & 33 & 16 \\
\hline GDI $($ mean $\pm 1 S D)$ & $75.6 \pm 13.2$ & $65 \pm 11.8$ & $60.1 \pm 9.3$ & $100 \pm 10$ & $100 \pm 10$ \\
\hline
\end{tabular}


Table 3

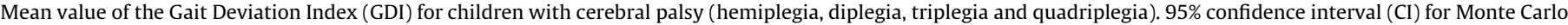
simulations for typically developing children (TD) and children with cerebral palsy, $95 \%$ confidence interval (CI) for the test-retest of the able-bodied group.

\begin{tabular}{|c|c|c|c|c|c|}
\hline & & $N$ & $\begin{array}{l}\text { GDI } \\
\text { Mean } \pm 1 \text { SD }\end{array}$ & $\begin{array}{l}\text { Test-retest } \\
(95 \% \mathrm{CI})\end{array}$ & $\begin{array}{l}\text { Monte-Carlo simulation } \\
(95 \% \mathrm{CI})\end{array}$ \\
\hline \multirow[t]{2}{*}{ TD children } & Reference group & 33 & $100 \pm 10$ & & 1.3 \\
\hline & Able-bodied group & 16 & $100 \pm 10$ & 10 & 1.3 \\
\hline \multirow[t]{2}{*}{ Hemiplegia } & Unaffected side & 31 & $81.2 \pm 11.4$ & & 1.5 \\
\hline & Affected Side & 31 & $71.9 \pm 13.3$ & & 1.5 \\
\hline Diplegia & & 86 & $66.3 \pm 13.1$ & & 1.2 \\
\hline Triplegia & & 6 & $69.6 \pm 9.9$ & & 1.2 \\
\hline Quadriplegia & & 11 & $58.1 \pm 6.5$ & & 0.8 \\
\hline
\end{tabular}

Power analysis based on the sample size of each group and their GDI mean showed an effect size of 0.4 and a power of $11.4 \%$ for triplegia group, $23.3 \%$ for quadriplegia, $35 \%$ for hemiplegia and 99.5\% for diplegia. One way Anova with Duncan post hoc test showed the ability of the GDI to distinguish between children with cerebral palsy, defined by their topographic classification, except between the affected side of hemiplegia and triplegia $(p=0.57)$ and between diplegia and triplegia $(p=0.38)$. Anova with Duncan post hoc test was applied and showed the ability of the GDI to distinguish between the three levels of GMFCS (I vs. II and I vs. III: $p<0.0001$, II vs. III: $p=0.022$ ). The Spearman Rank correlation showed a statistically significant moderate correlation between the GDI and the GMFCS $(r=-0.44$ with $p<0.0001)$.

\subsection{Database and repeatability for TD children}

The mean value of the GDI for the 33 TD children forming the reference group was $100.0 \pm 10.0$ (mean $\pm 1 \mathrm{SD}$ ). In the able-bodied group, the GDI had a mean value of $100.0 \pm 10.0$ (mean $\pm 1 S D$ ) (Table 3).

The test-retest with 2SD of the difference between the 2 sessions for the 16 TD children who passed the exam twice was \pm 10 (Table 3 ). The repeated measures of the GDI for the $16 \mathrm{TD}$ children are represented in Fig. 2 according to the Bland and Altman diagram. The equality of variances was verified by the Fisher test $(p=0.291)$. The $T$-test showed an insignificant difference between the mean values of the GDI in the first and the second session (97.3 \pm 8 at session 1 and $96.3 \pm 9$ at session $2, p=0.14$ ).

\subsection{Results of Monte Carlo simulations}

Ten thousand values of the GDI were obtained for each group of children with cerebral palsy. The 95\% confidence interval was calculated and was 1.3 for the able-bodied group $(N=16)$ and ranged between 0.8 and 1.3 for children with hemiplegia, diplegia, triplegia and quadriplegia (Table 3 ).

\section{Discussion}

In this study, the repeatability of the GDI for the 16 TD children who completed the exam twice was evaluated. The error propagation on GDI calculation for 49 TD subjects and 134 spastic children with CP was studied by applying Monte Carlo simulations. Correlation between the GDI and the GMFCS was assessed.

The test-retest study on TD subjects did not show any statistical differences between the mean values of the GDI in the first and second session $(p>0.05)$. This result gives further evidence that the GDI describes the overall gait profile. Between-session repeatability of the GDI was \pm 10 . Therefore, significant clinical changes could be detected only if the single value of the GDI decreases or increases more than 10 . Below 10 , the changes in values could be linked to an error related to the system of gait analysis, marker

Repeated measures of GDI on 16 Typically Developing children (Bland-Altman diagram)

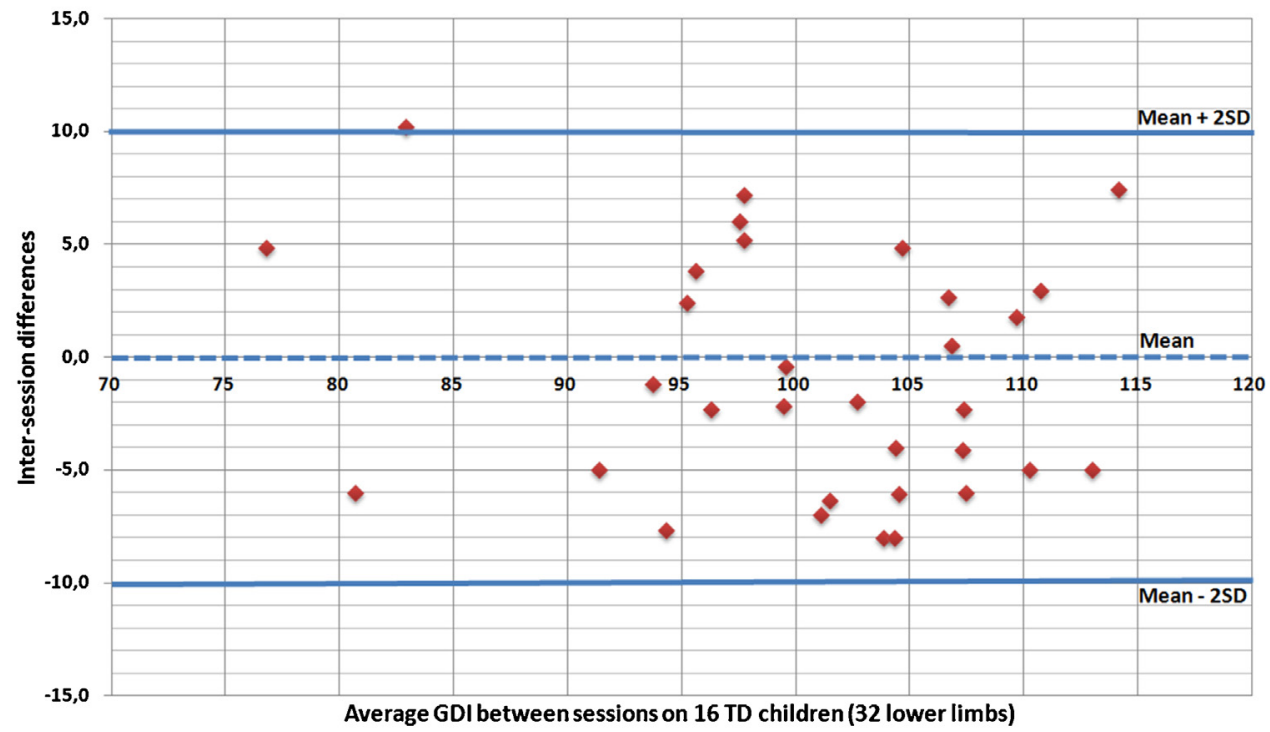

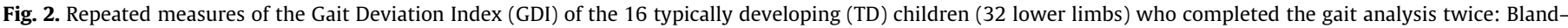
Altman diagram. 
placement and walking variability between the first and the second session, for the same subject.

The utility of Monte Carlo simulations is to observe how errors on the entry of a system can be propagated to the results. It would be useful to evaluate how any error on gait curves could affect the GDI value. In reality, errors that can affect kinematic curves can be due to many sources: intrinsic errors of the gait capture system, marker placement, soft tissue artifacts and the variability of the subject's walking profile between two sessions. The overall errors can be evaluated by a repeatability assessment (test-retest method) and can be presented as a 95\% confidence interval (CI) ( \pm 2SD of the difference between the 2 sessions) [14], which means that $95 \%$ of the uncertainties are included in this interval. When adding the entire margin of the $\mathrm{Cl}$ as a possible error on the kinematic curves in Monte Carlo simulations, we are assuming the worst case scenario and the maximum of errors that can occur. Error propagation on GDI calculation created an uncertainty ranging between 0.8 and 1.3. This uncertainty had the same range irrespective of the population on which the simulations were performed (typically developing children, hemiplegia, diplegia, triplegia and quadriplegia). Although, using the same standard deviation noise on the entries (kinematic curves) for all groups was a limitation, since data for children with $\mathrm{CP}$ was not available, the narrow range of uncertainty means that the GDI is robust, not sensitive to the noise applied on its entries.

The noise added on the kinematic curves to perform Monte Carlo simulations was based on the overall range of motion, of the joint angles, in each plane. Instead, the noise could be based on the point to point variability on the kinematic curves, between sessions. The first method was chosen because the repeatability of the overall range of motion is more significant in clinical practice.

It was shown in a previous study that the uncertainty on the GGI increases when the GGI value increases with the pathology [6]. This could be related to the fact that the GGI increases indefinitely with the pathology, which participates in the increase of the uncertainty, while the variation of the GDI is limited by a finite interval from 0 to 100 . It is relevant to note that the calculation of the GDI, based on the whole gait cycle, for each curve, could limit the propagation of errors, contrary to the GGI which uses well defined parameters, on each curve, during the gait cycle.

Thus, we can conclude that the uncertainty found in the testretest study on TD children $( \pm 10)$ could be the same for patients with $\mathrm{CP}$ and will not change with the pathology.

The ability of the GDI to distinguish between GMFCS levels concurs with the results found by Molloy [12] and by Schwartz for the Functional Assessment Questionnaire (FAQ)[7]. In this study, the GDI shows the ability to discriminate between different groups with cerebral palsy, defined by their topographic classification, except between the affected side of hemiplegia and triplegia as well as between diplegia and triplegia. This result could be explained by the post hoc power analysis, where limited power was found for the triplegia, quadriplegia and hemiplegia groups (11.4\%, 23.3\% and 35\% respectively) and high power for the diplegia group (99.5\%). Another interpretation of these findings could be related to the confusion in clinical classification of children with hemiplegia, diplegia and triplegia, based on clinical examination and visual assessment of gait abnormalities. The overlap of the value of the GDI noted for different groups with $C P$, defined by the topographic classification, indicates that the GDI could not be used as a diagnostic tool to classify children with $\mathrm{CP}$ but could give us information about the severity of impairments once the pathology is classified.

The mean value of the GDI for the unaffected side of hemiplegia is $81.2 \pm 11.4$, reflecting compensation behaviors for this side. GDI correlation with the GMFCS confirms its validity to give further information about motor impairments, even beyond walking abilities. Furthermore, the principle clinical utility of the GDI is to evaluate intervention outcomes [16], but it could not give us information about the location or the nature of changes. Some of these changes could be in part detected by the Gait Profile Score (GPS), which is closely related to the GDI [3]. Since the GDI does not take into consideration balance and stability, it would be interesting to study the correlation between the GDI and other scores that take into consideration balance and stability, which are affected by brain damage and could be improved after rehabilitation [17], an orthopedic treatment or other therapeutic interventions. The introduction of time distance parameters such as velocity, cadence, time of single support and double support, which are related to stability and balance [18], could give further information about the relation between kinematic parameters detected by the GDI and the improvement of motor control, after any therapeutic intervention in ambulant children.

\section{Acknowledgment}

The authors would like to thank Ziad El Bakouny for his assistance in the preparation for the manuscript.

\section{Conflict of interest statement}

All authors disclose any financial and personal relationships with other people or organisations that could inappropriately influence this work.

\section{References}

[1] Viehweger E, Haumont T, de Lattre C, Presedo A, Filipetti P, Ilharreborde B, et al. Multidimensional outcome assessment in cerebral palsy: is it feasible and relevant? J Pediatr Orthop 2008;28:576-83.

[2] Davis RB, Ounpuu S, Tyburski D, Gage JR. A gait analysis data collection and reduction technique. Hum Movement Sci 1991;10:575-87.

[3] Baker R, McGinley JL, Schwartz MH, Benyon S, Rozumalski A, Graham HK, et al. The gait profile score and movement analysis profile. Gait Posture 2009;30: 265-9.

[4] Schwartz MH, Novacheck TF, Trost J. A tool for quantifying hip flexor function during gait. Gait Posture 2000;12:122-7.

[5] Schutte LM, Narayanan U, Stout JL, Selber P, Gage JR, Schwartz MH. An index for quantifying deviations from normal gait. Gait Posture 2000;11:25-31

[6] Assi A, Ghanem I, Lavaste F, Skalli W. Gait analysis in children and uncertainty assessment for Davis protocol and Gillette Gait Index. Gait Posture 2009;30: 22-6.

[7] Schwartz MH, Rozumalski A. The Gait Deviation Index: a new comprehensive index of gait pathology. Gait Posture 2008;28:351-7.

[8] World Health Organization. International classification of functioning, disability and health. Geneva: World Health Organization; 2001.

[9] Hillman SJ, Hazlewood ME, Schwartz MH, van der Linden ML, Robb JE. Correlation of the Edinburgh Gait Score with the Gillette Gait Index, the Gillette Functional Assessment Questionnaire, and dimensionless speed. J Pediatr Orthop 2007;27:7-11.

[10] Romei M, Galli M, Fazzi E, Maraucci I, Schwartz M, Uggetti C, et al. Analysis of the correlation between three methods used in the assessment of children with cerebral palsy. Funct Neurol 2007;22:17-21.

[11] Tervo RC, Azuma S, Stout J, Novacheck T. Correlation between physical functioning and gait measures in children with cerebral palsy. Dev Med Child Neurol 2002;44:185-90.

[12] Molloy M, McDowell BC, Kerr C, Cosgrove AP. Further evidence of validity of the Gait Deviation Index. Gait Posture 2010;31:479-82.

[13] Bergamini E, Pillet H, Hausselle J, Thoreux P, Guerard S, Camomilla V, et al. Tibio-femoral joint constraints for bone pose estimation during movement using multi-body optimization. Gait Posture 2011;33:706-11.

[14] Bland JM, Altamn DG. Statistical methods for assessing agreement between two methods of clinical measurement. Lancet 1986;8476:307-10.

[15] Petrie A. Statistical power in testing a hypothesis. J Bone Joint Surg Br 2010;92: 1192-4.

[16] Rutz E, Baker R, Tirosh O, Romkes J, Haase C, Brunner R. Tibialis anterior tendon shortening in combination with Achilles tendon lengthening in spastic equinus in cerebral palsy. Gait Posture 2011; (February) 33(2):152-7.

[17] Shumway-Cook A, Hutchinson S, Kartin D, Price R, Woollacott M. Effect of balance training on recovery of stability in children with cerebral palsy. Dev Med Child Neurol 2003;45:591-602.

[18] Katz-Leurer M, Rotem H, Keren O, Meyer S. Balance abilities and gait characteristics in post-traumatic brain injury, cerebral palsy and typically developed children. Dev Neurorehabil 2009;12:100-5. 